\title{
Dynamic Model for Determining Technological and Economic Parameters for Precision Pigs Farming
}

\author{
Belma Gaazi, Plamen Daskalov, Tsvetelina Georgieva, and Eleonora Kirilova
}

\begin{abstract}
Dynamic model for determining technological and economic parameters for precision pigs farming is proposed in the paper. The model includes equations describing the temperature-humidity processes, growth, feed consumption and heating in the building, depending on the controlling inputs and the measurable disturbances movements on the building's microclimate. A cost-effective temperature is determined to maximize growth and minimize feed and energy consumption by using the Direct Search optimization procedure in Matlab. A cost effective temperature for 9 climatic zones of Bulgaria in winter season for fattening pigs $\mathbf{4 5}$ and 90 $\mathrm{kg}$ has been found. The economically efficient temperature for $45 \mathrm{~kg}$ pigs is determined between $20,86{ }^{\circ} \mathrm{C}-18,58{ }^{\circ} \mathrm{C}$ for different climatic zones of Bulgaria. For $90 \mathrm{~kg}$ pigs the economically efficient temperature is calculated and the results show that the temperature is the same for all climatic zones $-17.81{ }^{\circ} \mathrm{C}$..
\end{abstract}

Index Terms-Dynamic model, fattening pigs, cost-effective temperature, microclimate.

\section{INTRODUCTION}

The increase in electricity prices and increased technological requirements and the need to reduce production costs require the deployment of models and building systems to maintain optimum microclimate parameters in livestock buildings $[4,13,17]$. The microclimate in livestock breeding must provide an optimum animal environment, which in turn influences the growth, consumption of feed, which determines the economic efficiency of the production. One of the key components that increase productivity in agriculture is the choice of appropriate technology to manage, and it is related to the effective and economical use of energy resources with an opportunity to reduce costs in the production $[9,10,11,12$, 15,16 ]. Creation on model is useful instrument appled in a software program which facilitates further study of the variables that affect the environmental conditions inside a pig barn [20]. The main task in developing a model for controlling technological parameters is the choice of a suitable room temperature in which the obtain maximumgrowth and minimu m

\footnotetext{
${ }^{1}$ Manuscript received April 30, 2018; revised Jun 19, 2018. This work was supported Project No BG05M20P001-2.009-0011 "Support for the development of human resources in Research and Innovation at Ruse University 'A. Kanchev',.

The authors are with the Department of Autromatics and Mechatronics, University of Ruse, Ruse, Bulgaria (e-mail: bgaazi@uni-ruse.bg, pdaskalov@uni-ruse.bg, cgeorgieva@uni-ruse.bg, ekirilova@uni-ruse.bg).
}

feed consumption. The purpose is not to choose the biologically optimal temperature by a ordinance [1], but to calculate the cost-effective internal temperature in relation to the other factors influencing it [14].

\section{STRUCTURE OF THE MODEL}

The purpose of our study is a building for fattening pigs from 45 to $90 \mathrm{~kg}$. The building is equipped with contours for controlling natural ventilation and underfloor heating. The microclimate is considered as a dynamic system, which is formed from inputs divided into three distinct groups: biological and inter-climatic factors ( $\mathrm{Np}, \mathrm{m}, \mathrm{Gb})$, external natural factors (ta, da, Vw) and economical factors (PriceF, PriceQf, PriceM) (Figure 1). The outputs of the microclimatic dynamic system are Profit, Costs (RazhQf, RazhF) and the estimated cost-effective temperature (tb) that needs to be maintained in the room.

The overall dynamic model is a set of several models - a model for heating and humidification from animals, a heating model, a growth model, and a feed consumption model. The models have inputs that can be set by an operator. After starting the optimization in the model, the calculations are generated in search of an effective internal temperature for which maximum profit is obtained. Once the procedure has found the best temperature value, the optimization is terminated and the calculated cost, profit and economic optimum temperature are dis played.

- The model for heat and humidity from animals depends on the number of animals in the building, the mass of the animals and the temperature in the room;

- The influence factors of the heating model are outdoor temperature, outdoor humidity, wind speed, air exchange in the building, heating and humidity, and room temperature;

- The growth model depends on the temperature in the room and the number of animals;

- The feed consumption model also depends on the temperature in the room and the number of animals.

\section{ANALYTICAL DESCRIPTION OF THE MODEL}

\section{A. A model for Total Heat and Humidity from Animals}

A equation describing the heating of an animal according to kilograms $(2-100 \mathrm{~kg}$ ) expressed in $\mathrm{kW}$ derived from Strom [2] is as follow: 


$$
Q_{a t}=\left(29(m+2)^{0,5}-40 / 1000 .\right.
$$

where $Q_{a t}$ - latent heat from one animal, $\mathrm{m}$ - the mass of the animals in the building.

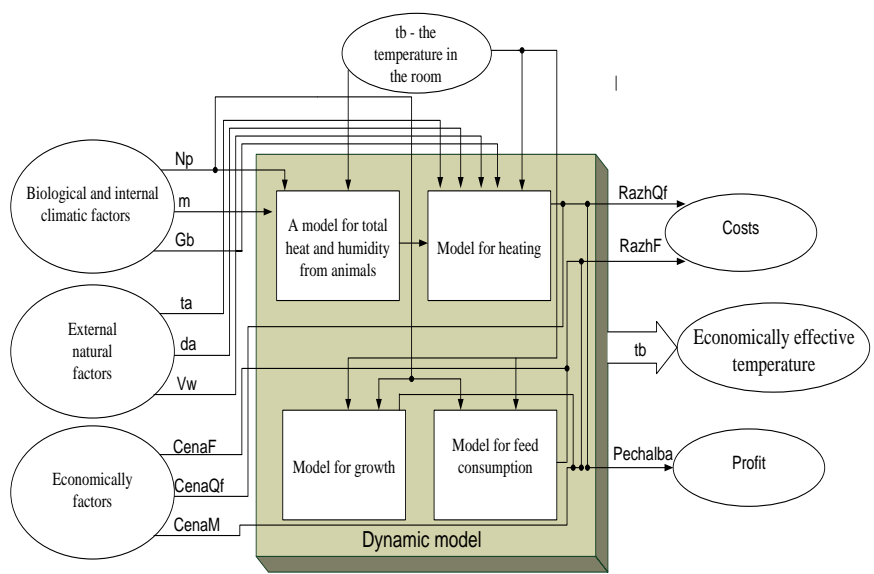

Fig. 1. Structure diagram of the dynamic model for calculating economical optimal temperature and economic parameters

The total heat emitted by all animals consists of latent and sensitive heat, the ratio of which depends on the temperature in the building. Equation 2 describes the total heat of all animals in the building in $\mathrm{kW} \mathrm{[2]:}$

$$
Q_{p}=N_{p} * Q_{a t}\left(0,8-1,85 * 10^{-7}(t b+10)^{4}\right) .
$$

where $\mathrm{Q}_{\mathrm{p}}$ - the total heat of all animals in the building, $\mathrm{N}_{\mathrm{p}}$ number of animals in the building, tb - the temperature in the room.

Equation 3, describes the total humidity of all animals in the building [18]:

$$
D_{p}=N_{p} * 0,001 *\left(0,26 * t b^{2}-6,46 * t b+81,6\right) .
$$

where $D_{p}$ - the total humidity of all animals in the building, $\mathrm{kg} /$ h.

\section{B. Model for Growth and Feed Consumption}

Data from [5], where graphically show the influence of room air temperature on the growth and feed consumption for 45 and $90 \mathrm{~kg}$, were used to obtain the desired models for fattening pigs.

- After the approximation of the data with least squares for growth of $45 \mathrm{~kg}$ fattening pigs (Fig. 2) it was obtained that the most appropriate equation describing the model for $45 \mathrm{~kg}$ pigs is a fourth degree polynomial with a correlation

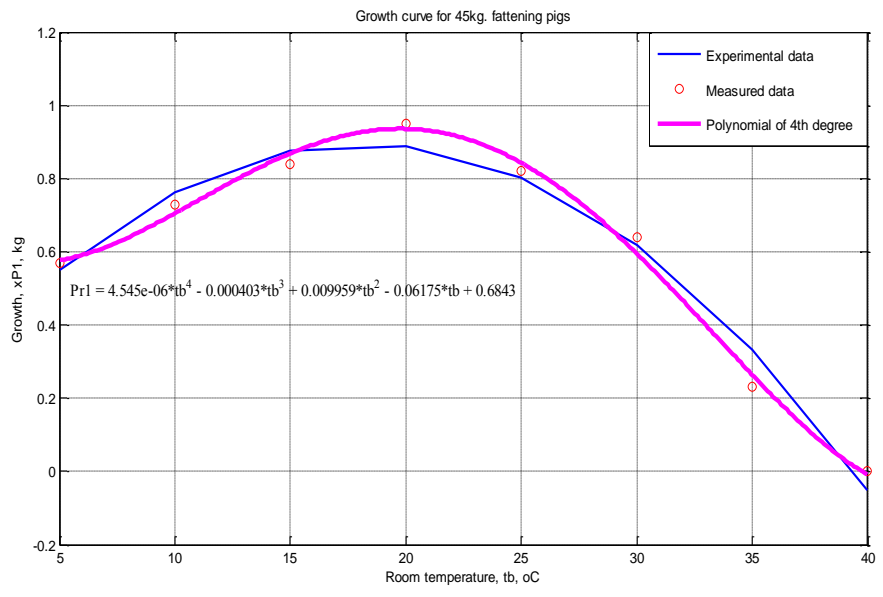

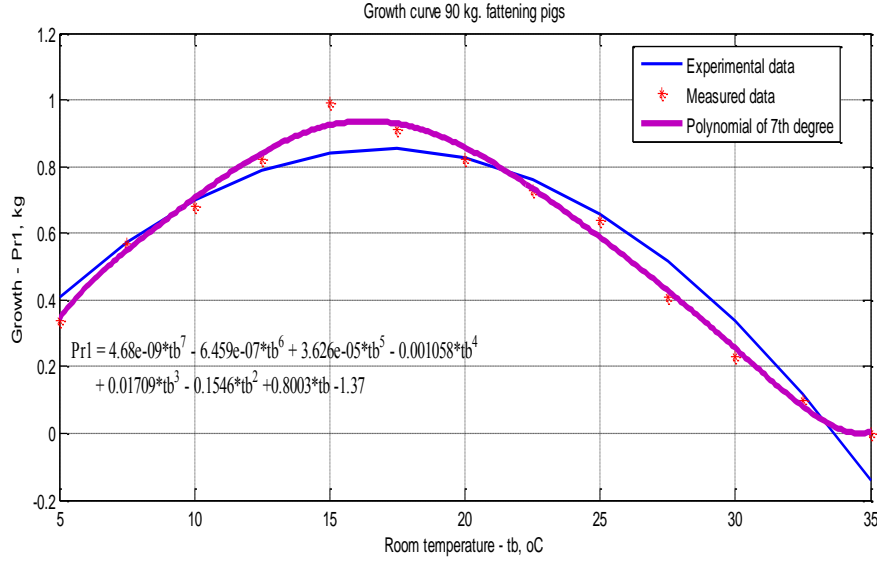

coefficient $\mathrm{R}^{2}=0.9955$ (4).

Figure 2. Influence of the room air temperature on the growth to $45 \mathrm{~kg}$ fattening pigs

$\operatorname{Prl}=4,545 e^{-6} * t b^{4}-0,000403 * t b^{3}+0,009959 * t b^{2}-$ $0,06175 * t b+0,6843$.

where Pr1 - growth of $45 \mathrm{~kg}$ for fattening pig per day, $\mathrm{kg}$.

- After the approximation on the data by least squares for $90 \mathrm{~kg}$ for fattening pigs is choice seventh degree polynomial with correlation coefficient $\mathrm{R}^{2}=0.9901$, which most accurately describes the measured data (5).

Figure 3. Influence of the room air temperature on the growth to $90 \mathrm{~kg}$ fattening pigs

$\operatorname{Pr} 1=4,68 e^{-9} * t b^{7}-6,459 e^{-7} * t b^{6}+3,626 e^{-5} * t b^{5}-$ $0,001058 * t b^{4}+0,01709 * t b^{3}-0,1546 * t b^{2}+0,8003 * t b$ $-1,37$.

- The feed consumption model is obtained by approximating the measured data using the least squares method. For $45 \mathrm{~kg}$ fattening pigs is a quadratic equation with correlation coefficient $R^{2}=0.99$ - (Fig. 4), which best describes the built curve (6).

Figure 4. Influence of the room air temperature on the feed consumption for $45 \mathrm{~kg}$ fattening pigs

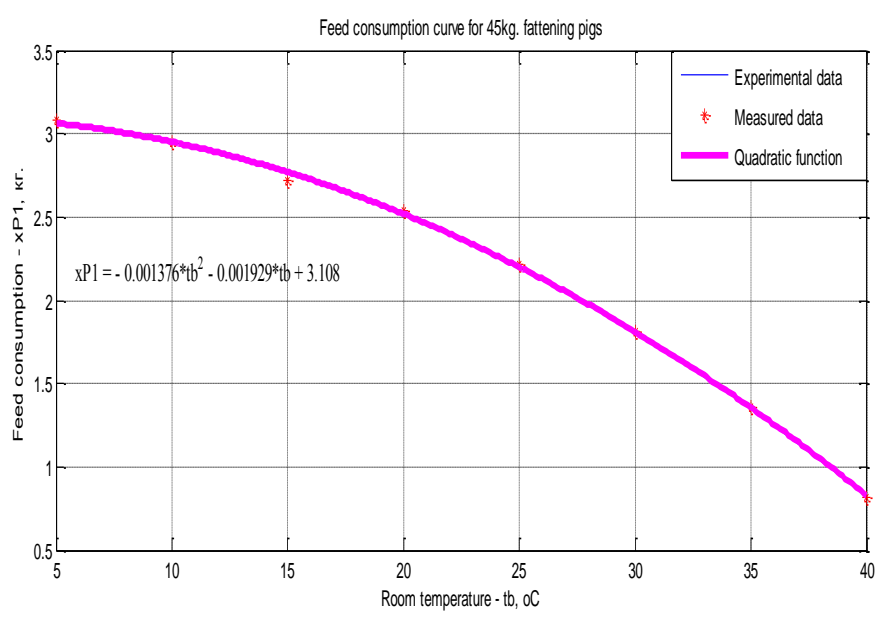

$x P 1=-0,0013762 * t b 2-0,0019286 * t b+3,1082 .(6)$

where $\mathrm{xP1}$ - the amount of feed needed for $1 \mathrm{pig}, \mathrm{kg}$. 
- The feed consumption model for $90 \mathrm{~kg}$ fattening pigs is a cubic equation with correlation coefficient $\mathrm{R}^{2}=0.99-$ (Fig.5) with (7).

$x P 1=-0,0001003 * t b^{3}+0,001602 * t b^{2}-0,02984 * t b+$ 4,168 .

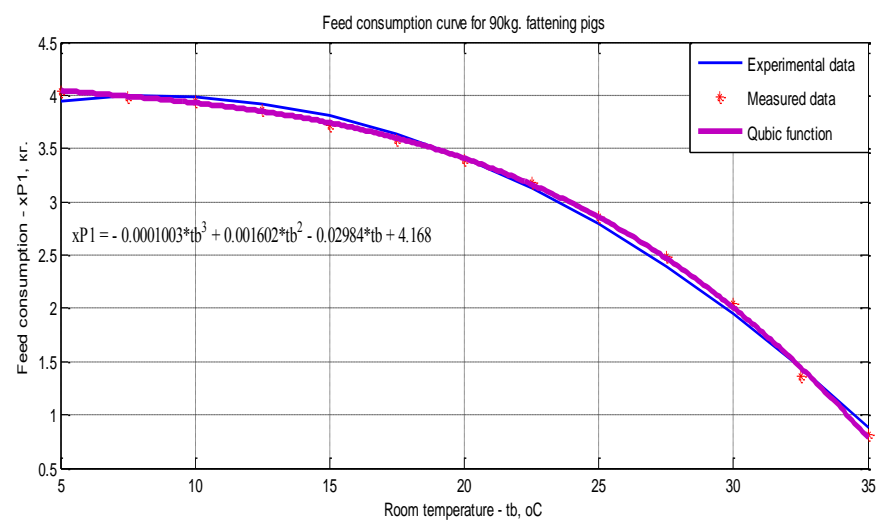

Fig.5. Influence of the room air temperature on the feed consumption for $90 \mathrm{~kg}$ fattening pigs

\section{Model for heating a pig farm}

The heating model is derived from [3], the parameter $\mathrm{Q}_{\mathrm{f}}$ representing the heat emitted by the underfloor heating in the building in kilowatts $(\mathrm{kW})$ :

$Q_{f}=\left[t b-\left(b_{g 1} * t_{a}+b_{g 2} * d_{a}+b_{g 3} * V_{w}+b_{g 4} * G_{b}+b_{g 6}\left(D_{c}+\right.\right.\right.$

$\left.\left.\left.D_{p}\right)\right)\right] / b_{g 5}-Q_{p}$

$b_{\mathrm{g} 1} \ldots b_{\mathrm{g} 6}$, are coefficients representing the steady-state transfer on the building;

$\mathrm{t}_{\mathrm{a}}$ - outside temperature, ${ }^{\circ} \mathrm{C} ; \mathrm{d}_{\mathrm{a}}$ - external moisture content, $\mathrm{g} / \mathrm{kg} ; \mathrm{V}_{\mathrm{w}}$ - wind speed, $\mathrm{m} / \mathrm{s} ; \mathrm{G}_{\mathrm{b}}$ - measured amount of ventilated air through the building envelope, $\mathrm{m}^{3} / \mathrm{h} ; \mathrm{D}_{\mathrm{c}}$ - pulsated water flow rate for cooling air, $\mathrm{kg} / \mathrm{h} ; \mathrm{D}_{\mathrm{p}}$ - the production of water vapor from pigs, $\mathrm{kg} / \mathrm{h} ; \mathrm{Q}_{\mathrm{p}}$ - Sensitive heat from pigs, $\mathrm{kW}$.

The use of (8) allows the amount of heat to be determined in winter. For this purpose it is assumed that the additional moisture for humidifying the building air is $D_{c}=0$ in the winter heating period and the variables $t_{a}, d_{a}$ and $V_{w}$ are taken on the average for the season. The air exchange in the building $G_{b}$ is based on minimal ventilation rate to the humidity balance in the building.

Equation (8) allows the amount of heat to be determined in winterheating season. For this purpose it is assumed that the additional moisture for humidifying the air in the building in the winter heating period, and the variables are taken in the average for the season. The air exchange in the building is based on minimal ventilation rate to the humidity balance of the building.

\section{Output economic parameters of the model}

\section{- Cost equations}

The economic parameters include the cost of electricity for heating and the costs associated with the amount of feed consumptions. Based on the average prices of the feed, we can assume that the price is $300 \mathrm{BGN}$ per ton, whose value is input and can be changed. The electricity price for business clients currently operating on average is around 0,20 BGN / $\mathrm{kWh}$ [6]. Cost equations are:

$$
\begin{gathered}
R a z h Q_{f}=Q f * \text { CenaQf*24. } \\
\text { RazhF }=J * \text { CenaF. }
\end{gathered}
$$

where RazhQ $\mathrm{Q}_{\mathrm{f}}$ - heating costs for 24 hours in BGN; CenaQf average electricity price for business customers, BGN / $\mathrm{kWh}$; RazhF - cost of feed, BGN; J - required amount of feed for all animals in the building, $\mathrm{kg}$; CenaF - price of feed, BGN / kg.

- Equation for profit

Profit is calculated from all growth in BGN subtracting the cost of heating and feed:

$$
\text { Pechalba }=-\left(P_{-} L v-\left(R a z h Q_{f}+R a z h F\right)\right) .
$$

where Pechalba - profit, lv; Pr_Lv - total growth, BGN.

\section{OPTIMIZATION PROCEDURE AND CALCULATION OF THE COST EFFECTIVE ROOM TEMPERATURE}

To find the cost-effective temperature ' $t b$ ' we use the optimization procedure "pattern search". This procedure uses the Direct Search method that solves optimization tasks, which do not require information about the target function's gradient. Therefore, it can also be applied in the optimization of undifferentiated and discontinued functions. In this case, the direct search has a larger field of application in comparison with the gradient method and their inferior in fast response [7]. The function, which must be minimized / maximized, accepts the vector tb and returns as a solution to the scalar function evaluated by 'tb':

$[\mathrm{tb}, \mathrm{fval}]=$

patternsearch(fun,x0,A,b,Aeq,beq,lb,ub,nonlcon,options)

- $\mathrm{tb}$ - Solution;

- fval - Objective function value at the solution;

- patternsearch - optimization procedure;

- fun - Objective function;

- $\mathrm{x} 0$ - Initial point, specified as a real vector, patternsearch uses the number of elements in $\mathrm{x} 0$ to determine the number of variables that fun accepts;

- A - Linear inequality constraints, specified as a real matrix.;

- b - Linear inequality constraints, specified as a real vector;

- Aeq - Matrix for linear equality constraints;

- beq - Vector for linear equality constraints;

- $\mathrm{lb}$ - Lower bound for ' $\mathrm{tb}$ ';

- ub - Upper bound for 'tb';

- nonlcon - Nonlinear constraint function;

- The "patternsearch" procedure of each iteration performs the following basic operations:

1) Generate multiple points of the so-called mesh - network;

2) Selecting from the network a point for which the target function has a value lower than the current polling. This point becomes current; 
3) Correcting network size;

4) Check the criteria for terminating the calculation.

\section{ALGORITHM OF THE MODEL FOR CALCULATION AND OPTIMIZATION:}

1. Operator level - the required operator data required for the computation procedures is entered.

2. Software level - model parameters are cleared based on the patternsearch optimization procedure.

After starting the optimization procedure, which cyclically calculates the output values of the model at different temperatures and finds the above-described economically most effective temperature ' $t b$ ' inside the room at which obtained maximum profit based on the other factors introduced by an operator, affecting the building's microclimate - Fig. 6 .

3. Control level - after receiving the cost effective temperature, the received information is visualized with the ability to control the microclimate in the room.

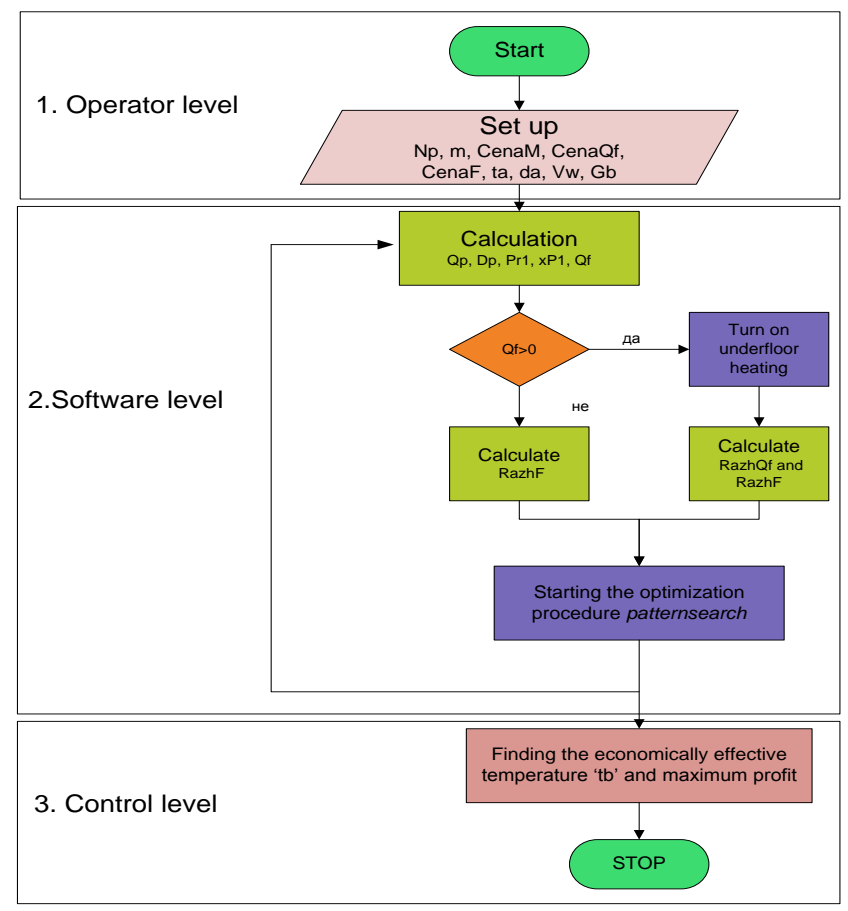

Figure 6. Algorithm for finding the cost-effective temperature in a pig farm

\section{SIMULATION RESULTS}

Simulation tests were conducted in the Matlab environment, and the influence of outdoor temperature during the winter heating season on the internal temperature in the pig farm was assessed. In Bulgaria the heater winter season is relatively long and most important, in terms of costs. There are 9 climate zones [8] (Table 1), where the external computing temperature varies, and necessary to define in which areas which temperature in pig buildings should be maintained to obtain maximum production with minimum costs.

TABLE I. COMPUT ATIONAL OUT SIDE TEMPERATURE FOR THE WINTER HEATING SEASON FOR THE CLIMATIC ZONES OF BULGARIA [8]

\begin{tabular}{|||l||l||c||}
\hline № & Climate zone & $\begin{array}{c}\text { Calculated } \\
\text { outside } \\
\text { temperatur } \\
\text { e }\end{array}$ \\
\hline \hline 1 & Northern Black Sea coast & $-11^{\circ} \mathrm{C}$ \\
\hline 2 & Dobrudja & $-15^{\circ} \mathrm{C}$ \\
\hline \hline 3 & $\begin{array}{l}\text { Northern Bulgaria - the valley of the Danube } \\
\text { River }\end{array}$ & $-17^{\circ} \mathrm{C}$ \\
\hline \hline 4 & Northern Bulgaria - central part & $-17^{\circ} \mathrm{C}$ \\
\hline \hline 5 & Southern Black Sea Coast & $-10^{\circ} \mathrm{C}$ \\
\hline 6 & Southern Bulgaria - central part & $-15^{\circ} \mathrm{C}$ \\
\hline \hline 7 & Sofia and the sub-Balkan valley & $-16^{\circ} \mathrm{C}$ \\
\hline \hline 8 & Southern Bulgaria & $-14^{\circ} \mathrm{C}$ \\
\hline \hline 9 & Southwest Bulgaria & $-10^{\circ} \mathrm{C}$ \\
\hline
\end{tabular}

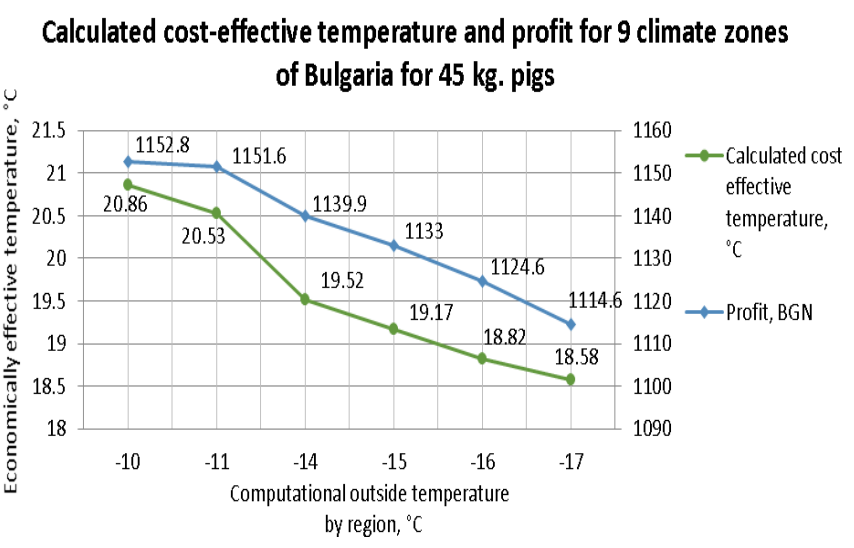

Have been research with simulation tests for 45 and $90 \mathrm{~kg}$ for fattening pigs and the external computational temperature for different climatic zones of Bulgaria was changed. Figure 7 presents the graphically calculated cost-effective temperature and the profit obtained for the nine climatic zones of Bulgaria for $45 \mathrm{~kg}$ for fattening pigs.

Figure 7. Graphical data for calculated internal economic efficiency temperature and profit for 9 climatic zones of Bulgaria for $45 \mathrm{~kg}$ fattening pigs

Research carried out for $90 \mathrm{~kg}$ fattening pigs with change in the external computational temperature for different climatic zones of Bulgaria have found a cost-effective temperature of $17.81^{\circ} \mathrm{C}$ for all climatic zones, giving the fact that older pigs can tolerate lower temperatures without affecting their health [19]. The larger the pig, the lower the LCT (Low Critical Temperature).

\section{CONCLUSION}

Simulation experiments were performed for 45 and $90 \mathrm{~kg}$ fattening pigs in the Matlab environment with a dynamic optimization model for determining the cost effective temperature for the winter heating seas on for 9 climatic zones of Bulgaria. The results show that for $45 \mathrm{~kg}$ pigs economic efficiency temperature is between $20.86{ }^{\circ} \mathrm{C}$ and $18.58{ }^{\circ} \mathrm{C}$ for different climate zones of Bulgaria. For $90 \mathrm{~kg}$ pigs the temperature is $17.81{ }^{\circ} \mathrm{C}$ for all climatic zones due to the fact that older pigs can adapt and tolerate the lower temperatures [19]. According to the results obtained from an economic point of 
view, it is advisable to grow younger pigs in the warmer climatic zones of Bulgaria.

\section{ACKNOWLEDGMENT}

This article was prepared with the financial support of the European Social Fund.

Project No BG05M20P001-2.009-0011 "Support for the development of human resources in Research and Innovation at Ruse University 'A. Kanchev”'.

\section{REFERENCES}

[1] Veterinary and zoo-hygiene requirements for livestock holdings for farm animals, Ordinance No 44 / 20.04.06, SG No. 41 / 19.05.06.

[2] H. Bartussek, J. Christiaens, S. Pedersen et al, CIGR Climatisation of Animal Houses, ISBN 090243333 4, 1984.

[3] P. I. Daskalov, "Prediction of temperature and humidity in a nat urally ventilated pig building," J. agric. EngngRes, vol. 68, pp. 68, 329-339 1997.

[4] H. Heitman, T.E. Bond, and C.F. Kelly, "Effect of temperature on swine," California Agriculture, 1954.

[5] Dejstvashti. [Online]. ata-Stopanski-klienti

[6] Y. Tonchev and V. Vitliemov, Matlab Optimization, Ruse University Publishing “Angel Kanchev,” Ruse, 2013.

[7] Government. [Online]. Available: http://www.seea.government.bg/documents/Naredba-RD-16-1058 .pdf

[8] F. Kuhlmann and C. Brodersen, "Information technology and farm management: Developments and perspectives," Computers and Electronics in Agriculture, vol. 30, pp. 71-83, February 2001.

[9] A. Kaloxylos, R. Eigenmann, and F. Teye, "Farm management systems and the future internet era," Computers and Electronics in Agriculture, vol. 89, pp. 130-144, November 2012.

[10] S. Cox, "Information technology: the global key to precision agriculture and sustainability," Computers and Electronics in Agriculture, vol. 36, pp. 93-111, November 2002.

[11] L.W. Tauer and A. K. Mishra, "Dairy farm cost efficiency," Journal of Dairy Science, vol. 89, Issue 12, pp. 4937-4943, December 2006.

[12] A. L. Barriuso, G. V. González, J. F. D. Paz, A. Lozano, and J. Bajo, "Combination of multi-agent systems and wireless sensor net works for the monitoring of cattle," Sensors, vol. 18, 2018.

[13] A. A. Lebedi, "Technique of rationing of microclimate of livestock and poultry houses," Engineering in Agriculture, no. 2, 1988.

[14] S. Sindhu and D. Sindhu, "Information dissemination using computer and communication technologies for improving agriculture productivity," International Journal of Emerging Trends \& Technology in Computer Science (IJETTCS), vol. 6, Issue 6, 2017.

[1] O. N. Polozyuk and T. I. Lapina, "The influence of housing conditions on the fattening and meat quality of animals," The Agrarian Scientific Journal, 2016.

[2] Y. Duan, L. Ma, C. Zhang, G. Liu, X. Ma, and L. Li, "A remote monitoring system for physiology and environmental information in pig farming," American Society of Agricultural and Biological Engineers /ASABE/, St. Joseph, Michigan, 2014.

[3] ASHRAE Handbook of Fundamentals, 1981.

[4] business-Priorities. [Online].

Available: https://www.daf.qld.gov.au/business-priorities/animal-industries/pi gs/managing-a-piggery/housing-pigs/basic-housing-requirements.

[5] P. Liberati and P. Zappavigna, "A dynamic computer model for optimizationof the internal climate in swine housing design," Transactions of the ASABE, vol 50, pp. 2179-2188, 2007.

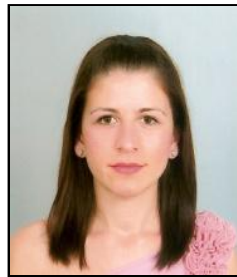

Belma Gaazi was born in Ruse, Bulgaria, in 1986. She received the B.S. degree from the Ruse University in 2010 and the M.S. degree from the Ruse University in 2011, both in automation engineer. She is currently pursuing the Ph.D. degree with the Department of Automatic and Mechatronic, Ruse University. Hers research interests include modeling, optimization, and graphical user interfaces

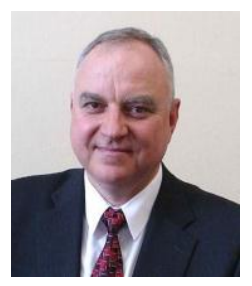

Plamen Daskalov was born in Ruse, Bulgaria, in 1958. He graduated HT S “Angel Kanchev” - Ruse in 1984 - Engineer in Automation of production. He defended his PhD thesisn 1992. In 2000 year he is elected assoc. professor. In 2012 year he is elected professor in automation of production. In 2016 year elected vice rector in Development, Coordination and Continuing Education and Director of the Centre for Continuing Education with the University of Ruse "Angel Kanchev". His research interests include Identification and modelling of process and systems in agriculture; Application of computer systems and IT in managing the technological processes in precise farming; Automation of processes in livestock buildings and greenhouses; Evaluation of quality of agricultural products via digital images and spectral characteristics.

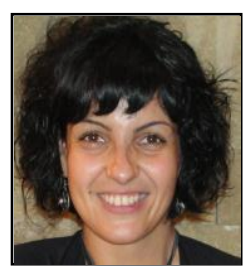

Tsvetelina Georgieva was born in Kozloduy, Bulgaria, in 1978. She received the B.S. degree from the Ruse University in 2003 and the M.S. degree from the Ruse University in 2004, both in aut omation engineer. She defended his $\mathrm{PhD}$ thesis in 2007. In 2012 year he is elected Assoc. professor. Hers research interests include industrial networks in computer control systems and evaluation of quality of agricultural products via digital images and spectral characteristics.

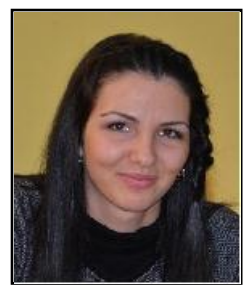

Eleonora Kirilova was born in Ruse, Bulgaria, in 1984. She received the B.S. degree from the Ruse University in 2006 and the M.S. degree from the Ruse University in 2007, both in automation engineer. She defended his PhD thesis in 2013. Hers research interests include evaluation of quality of agricultural products via digital images and spectral characteristics. 